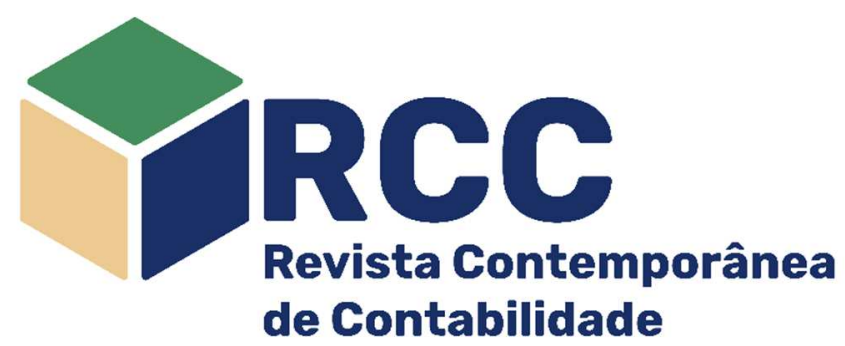

\title{
Economias de escala nas entidades fechadas de previdência complementar brasileiras: existe um tamanho ótimo?
}

\author{
Economies of scale in Brazilian closed supplementary pension entities: is there an optimal size?
}

Economías de escala en las entidades de pensiones privadas brasileñas: ¿hay un tamaño óptimo?

\author{
Rudolph Fabiano Alves Pedroza Teixeira* \\ Doutorando em Ciências Contábeis (UFRJ) \\ Profissional da Nível Superior da Centrais Elétricas \\ Brasileiras (ELETROBRAS), Rio de Janeiro/RJ, Brasil \\ rudolphteixeira@gmail.com \\ http://orcid.org/0000-0001-5325-5267 (0)
}

\author{
Adriano Rodrigues \\ Doutor em Controladoria e Contabilidade (USP) \\ Professor do Programa de Pós-Graduação em Ciências \\ Contábeis (UFRJ), Rio de Janeiro/RJ, Brasil \\ adriano@facc.ufrj.br \\ https://orcid.org/0000-0002-0099-0505 (c)
}

Endereço do contato principal para correspondência* Avenida Pasteur 250, Sala 250, Ǔrca, CEP: 22.290-240 - Rio de Janeiro/RJ, Brasil

\begin{abstract}
Resumo
A pesquisa investigou a existência de um tamanho ótimo para a operação das Entidades Fechadas de Previdência Complementar (EFPC) brasileiras, com base em suas despesas administrativas. Em outras palavras, foi verificado se os fundos de pensão brasileiros gozariam de economias de escala até um determinado ponto, a partir do qual, a complexidade das grandes estruturas passaria a provocar deseconomias de escala. Como pano de fundo foi utilizada a teoria da organização industrial com enfoque nas barreiras à entrada. Os resultados comprovaram que as despesas administrativas das EFPC se comportam na forma de "U", o que significa que existe um tamanho ótimo para operação dessas entidades. Esse achado fornece importantes elementos que podem subsidiar o órgão regulador do setor a restringir a entrada de novos fundos nesse mercado, o que traria benefícios a todos os participantes das EFPC em termos de redução de custos e ampliação da poupança previdenciária.
\end{abstract}

Palavras-chave: Barreiras à Entrada; Despesas Administrativas; Economias de Escala; EFPC; Tamanho Ótimo

\begin{abstract}
This research investigated the existence of an optimal size for the operation of Brazilian Closed Supplementary Pension Entities (CSPE), based on their administrative expenses. Otherwise stated, we verified whether the Brazilian pension funds would benefit from economies of scale up to a certain point, after which the complexity of the large structures would cause diseconomies of scale. As a background, we used the theory of industrial organization with a focus on entry barriers. The results showed that CSPE administrative expenses behave in a "U" shape, which means that there is an optimal size for these entities' operation. This finding provides important elements to subsidize the industry's regulatory body to restrict the entry of new funds in this market, which would benefit all CSPE participants in cost reduction and expansion of social security savings.
\end{abstract}

Keywords: Entry Barriers; Administrative Expenses; Economies of Scale; CSPE; Optimal Size

\section{Resumen}

La presente investigación investigó la existencia de un tamaño óptimo para la operación de las Entidades de Pensiones Complementarias Cerradas de Brasil (EPCC), con base en sus gastos administrativos. En otras palabras, se verificó si los fondos de pensiones brasileños disfrutarían de economías de escala hasta cierto punto, después de lo cual, la complejidad de las grandes estructuras causaría deseconomías de escala. Como antecedente, se utilizó la teoría de la organización industrial con un enfoque en las barreras de entrada. Los resultados demostraron que los gastos administrativos de EPCC se comportan en forma de "U", lo que significa que hay un tamaño óptimo para la operación de estas entidades. Este hallazgo proporciona elementos importantes que pueden subsidiar el organismo regulador del sector para restringir la entrada de 
nuevos fondos en este mercado, lo que traería beneficios a todos los participantes de EPCC en términos de reducción de costos y expansión de los ahorros de la seguridad.

Palabras clave: Barreras a la entrada; Gastos administrativos; Economías de escala; EPCC; Tamaño óptimo

\section{Introdução}

As entidades fechadas de previdência complementar (EFPC) ou fundos de pensão são organizações constituídas na forma de fundação ou sociedade civil, sem fins lucrativos, que possuem a função de administrar planos previdenciários coletivos, acessíveis somente a empregadoslservidores de uma patrocinadora ou a pessoas que tenham vínculo associativo com um instituidor (Lei Complementar № 109, 2001).

Essas entidades apresentam uma enorme responsabilidade social, pois, além de terem a guarda dos recursos de mais de 3,5 milhões de pessoas no Brasil (Associação Brasileira das Entidades Fechadas de Previdência Complementar, 2019), elas também são responsáveis por gerir e aplicar esses recursos de forma eficiente e eficaz, buscando um equilíbrio entre risco e retorno, conforme as diretrizes da Resolução no 4.661, de 25 de maio de 2018, editada pelo Conselho Monetário Nacional (CMN).

Entretanto, a constituição e manutenção de uma EFPC demandam recursos para cobrir despesas administrativas diversas com seus planos de benefícios; carteira de investimentos; salários de funcionários; serviços advocatícios; consultoria atuarial e financeira; serviços de tecnologia da informação (TI); entre outros (Bateman \& Mitchell, 2004).

Nesse sentido, verifica-se que o gerenciamento eficiente das despesas administrativas é um tema relevante para a defesa dos interesses de participantes, patrocinadoras e instituidores, já que os recursos utilizados na manutenção dos fundos de pensão deixam de ingressar na poupança previdenciária dos planos de benefícios pós-emprego (Superintendência Nacional de Previdência Complementar, 2020c).

A esse respeito, Ambachtsheer (2010) afirma que as economias de escala das EFPC possuem papel fundamental na concessão de bons benefícios de aposentadoria, pois os fundos com menores despesas administrativas per capita seriam os responsáveis por maximizar a riqueza acumulada de seus participantes, visto que gastariam menos com sua manutenção.

Um aspecto primordial para a ocorrência de economias de escala recai na parcela dos custos fixos. Segundo Besanko et al., (2009) esses seriam diluídos pela expansão da produção, compensando o comportamento constante dos custos variáveis, o que proporcionaria a redução do custo unitário. No caso dos fundos de pensão, Bikker e De Dreu (2009) afirmam que os custos fixos por serem inelásticos em relação ao número de participantes e aos ativos financeiros representam grande parte das economias de escala não exploradas, principalmente, por atividades como: comunicação; conformidade; obrigações contábeis e regulatórias; sistemas de $\mathrm{Tl}$, etc.

Todavia, Bikker (2017) também pondera que em decorrência dessa aparente elevada inelasticidade custo, a pesquisa teórica e empírica sobre as EFPC tem se concentrado basicamente em descrever a função custo como em declínio monotônico. Na visão desse autor, alguns fundos podem estar operando acima de sua capacidade produtiva, gerando deseconomias de escala para seus participantes.

Parte literatura vinculada a organização industrial tem fornecido evidências de que os custos em grandes empresas podem aumentar mais que proporcionalmente, após essas atingirem um determinado tamanho. Isso significa que os custos unitários na verdade não teriam um comportamento continuamente decrescente em relação a quantidade produzida, mas sim, na forma de "U". Por exemplo, Griffin e Tversky (1992) argumentam que a escassez de pessoal qualificado, o aumento do luxo nos edifícios corporativos e os altos salários dos executivos podem gerar custos adicionais às grandes empresas.

Canback, Samouel e Price (2006) consideram que nas grandes firmas o comprometimento dos funcionários pode ser menor, tendo em vista que eles contribuiriam pouco para o sucesso da organização, 0 que resultaria em menor produtividade. Por sua vez, Bauer, Cremes e Frehen (2010) mencionam que a comunicação entre os diferentes departamentos e a necessidade de monitoramento dos funcionários em grandes empresas geram custos crescentes. Ainda sobre isso, Chatterton, Smyth e Darby (2010) afirmam que a ineficiência das grandes firmas pode ter origem na burocracia vinculada aos complexos organogramas dessas entidades, que teriam diversos níveis hierárquicos para serem gerenciados.

O objetivo da pesquisa é investigar a existência de um tamanho ótimo para a operação das Entidades Fechadas de Previdência Complementar (EFPC) brasileiras, com base em suas despesas administrativas. Em outras palavras, pretende-se verificar se os fundos de pensão brasileiros gozariam de economias de escala até um determinado ponto, a partir do qual, a complexidade das grandes estruturas passaria a provocar deseconomias de escala.

Vale destacar que o presente estudo se justifica pela necessidade de fornecer elementos ao Conselho Nacional de Previdência Complementar (CNPC), órgão regulador do setor, quanto a criação de novas barreiras à entrada nesse mercado, estimulando sua concentração. Diversos trabalhos como os de Mitchell e Andrews (1981); Bateman e Mitchell (2004); Bikker e De Dreu (2009) e; Cunha (2018) comprovaram a existência de economias de escala no setor de previdência complementar fechada, quando considerada uma 
função custo com comportamento monotônico. No entanto, até onde se tem conhecimento, apenas o estudo de Bikker (2017) para as EFPC holandesas, calculou o tamanho ótimo para o mercado de previdência complementar fechado considerando um comportamento de "U" para seus custos. Sendo assim, observa-se que a presente pesquisa também ajuda a preencher tal lacuna na literatura brasileira.

Para tanto o estudo de Bikker (2017) será replicado, em que serão testados quatro tipos de funções custo quadráticas na forma de "U", com a intenção de explicar as despesas administrativas previdenciais e com investimentos dos fundos de pensão no Brasil. No que se refere as despesas previdenciais, será utilizado como principal insumo das equações a quantidade total de participantes (ativos e inativos), isto é, a população total do fundo, que captura a gestão previdencial. Por sua vez, para as despesas com investimentos, a principal variável será o total de ativos financeiros das EFPC, que representa a parcela atrelada a gestão financeira.

\section{As Principais Características das EFPC Brasileiras}

De acordo com Pereira, Niyama e Sallaberry (2013) e Pasqualeto (2015), o regime de previdência complementar no Brasil é dividido em dois tipos. O primeiro compreende as entidades abertas de previdência complementar (EAPC), organizadas sob a forma de sociedades anônimas e administradas por instituições financeiras e seguradoras, sendo acessíveis a todos os cidadãos. Já o segundo refere-se às EFPC, que são constituídas na forma de fundação ou sociedade civil sem fins lucrativos, sendo acessíveis aos empregados de empresas públicas ou privadas, servidores da União, do Distrito Federal, dos Estados e dos municípios, suas autarquias e fundações, sendo esses entes denominados de patrocinadores. Além disso, tal sistema engloba associados a pessoas jurídicas de caráter profissional, classista ou setorial, denominadas de instituidores.

No que concerne as EFPC, a grande vantagem para seus participantes reside não somente nos recursos que eles aportam para sua poupança previdenciária, mas também, nas contribuições efetuadas pelas patrocinadoras, que na maior parte dos casos são paritárias as efetuadas pelos participantes, o que gera um efeito catalizador sobre o volume de recursos acumulados.

Conforme pode ser observado na Tabela 1, entre os anos de 2017 e 2018 as EFPC brasileiras contavam com uma média de 2,95 milhões de participantes entre ativos e inativos (aposentados e pensionistas), tendo mais de $\mathrm{R} \$ 861,5$ bilhões em recursos investidos. Além disso, cada participante tinha para o mesmo período uma média $R \$ 292$ mil reais acumulados, nos mais de 940 planos de benefícios pósemprego ofertados pelas EFPCi analisadas.

Tabela 1:

Principais Estatísticas das EFPC brasileiras

\begin{tabular}{|c|c|c|}
\hline $\begin{array}{ll} & \text { Descrição } \\
\end{array}$ & 2017 & 2018 \\
\hline Total de Despesas Previdenciais (em bilhões $R \$$ ) & 1,86 & 1,78 \\
\hline Total de Despesas com Investimentos (em bilhões $R \$$ ) & 1,14 & 1,15 \\
\hline Despesas Administrativas per capita (em mil $\mathrm{R} \$$ ) & 1,05 & 0,97 \\
\hline Número de Participantes (em milhões) & 2,87 & 3,03 \\
\hline Total de Ativos (em bilhões $R \$$ ) & 842,54 & 880,52 \\
\hline Despesas Administrativas sobre Total de Ativos & $0,22 \%$ & $0,20 \%$ \\
\hline Ativos per capita (em mil R\$) & 294,03 & 290,40 \\
\hline Maturidade Média (benefícios a conceder/concedidos) & 7,14 & 5,24 \\
\hline Solvência Média (prov. matemáticas/patrim. cobertura) & 1,07 & 1,03 \\
\hline Planos CD & 399 & 416 \\
\hline Planos BD & 279 & 230 \\
\hline Planos CV & 294 & 295 \\
\hline Terceirizaccão sobre Despesas Administrativas (média) & $33,97 \%$ & $40,27 \%$ \\
\hline Total de EFPC & 225 & 230 \\
\hline EFPC Públicas Federais & 33 & 33 \\
\hline EFPC Públicas Estaduais & 36 & 36 \\
\hline EFPC Públicas Municipais & 2 & 2 \\
\hline EFPC Privadas & 138 & 143 \\
\hline EFPC Instituídas & 16 & 16 \\
\hline EFPC no RJ, SP e DF & 140 & 144 \\
\hline EFPC nas demais regiões & 85 & 86 \\
\hline
\end{tabular}

Nota: Os valores de 2017 foram corrigidos a preços de 2018 pelo Índice Nacional de Preços ao Consumidor (INPC).

Fonte: Elaborado pelos autores com base em PREVIC (2020a); (2020b) e (2020c).

Nota-se também que no período 2017-2018, mais de 62\% das EFPC se localizavam em três das principais capitais brasileiras, isto é, Rio de Janeiro, São Paulo ou Brasília, com $61 \%$ de todas as EFPC sendo mantidas por empresas privadas, enquanto as EFPC com patrocínio predominantemente estatal corresponderam a aproximadamente $31 \%$ de todos os fundos de pensão. 
No que diz respeito ao tipo de plano ofertado por essas entidades, verifica-se que a maior parte se concentra na modalidade de contribuição definida (CD), sendo seguido pelos planos de contribuição variável (CV) e benefício definido (BD), com uma tendência de crescimento ao longo do tempo para o primeiro, em detrimento dos dois últimos, que possuem em sua essência riscos atuariais. Esse fato é corroborado pela resolução da Comissão Interministerial de Governança Corporativa e de Administração de Participações Societárias da União (CGPAR) ํำ25, de 6 de dezembro de 2018, em seu artigo 3ํㅜ que determina a criação de novos planos por parte de empresas estatais federais somente na modalidade CD.

Com relação à eficiência administrativa no período 2017-2018, o conjunto das EFPC gastou em média $R \$ 1,82$ bilhão com a gestão previdencial, que engloba o conjunto de atividades relacionadas ao atendimento de seus participantes e, $R \$ 1,14$ bilhão com a gestão de todos os seus investimentos, o que de forma consolidada representou uma despesa administrativa média per capita superior a $\mathrm{R} \$ 1$ mil por ano.

Também foi calculada a maturidade e a solvência das EFPC, de acordo com o recomendado pela Associação Nacional dos Contabilistas das Entidades de Previdência (ANCEP, 2020). A maturidade é dada pelo total de benefícios a conceder sobre o total de benefícios concedidos e indica a taxa de recursos mantidos pelos participantes ativos em relação aos recursos dos inativos. Uma maturidade menor que 1 (um) releva que o fundo está com mais recursos comprometidos com o pagamento de inativos, do que é mantido em reserva pelos ativos. No ano de 2017 existia aproximadamente 7 vezes mais recursos a serem concedidos pelas EFPC, do que os valores concedidos, com esse valor sendo da ordem de 5 para 1 no ano de 2018.

Já para a solvência, que é obtida pela divisão do total de provisões matemáticas pelo patrimônio de cobertura das EFPC, um valor superior a 1 (um) indica insuficiência de recursos para pagar a integralidade dos benefícios a todos os seus participantes. Considerando os anos de 2017 e 2018 é possível notar que esse indicador foi maior que a unidade, revelando que as EFPC do mercado em média são insolventes.

\section{A Teoria Clássica da Organização Industrial e as Barreiras à Entrada}

$\mathrm{Na}$ busca pela eficiência e competitividade as empresas devem ser capazes de avaliar e encontrar os principais determinantes de seu desempenho para implementarem ações estratégicas que as coloquem em vantagem sobre seus concorrentes já estabelecidos, bem como, em relação a potenciais entrantes no mercado, o que pode beneficiar toda indústria (Kupfer, 2002).

Em cada segmento industrial, o ingresso de novos concorrentes é dificultado pela existência de determinadas barreiras à entrada, que podem ser maiores ou menores, dependendo da indústria em questão. Assim, o adequado conhecimento destas barreiras torna-se fundamental para que as empresas adotem estratégias adequadas de sobrevivência.

O trabalho de Bain (1956) definiu o conceito de barreiras à entrada em um determinado mercado, como a distinção inicial existente entre as firmas já estabelecidas em uma indústria, produzindo para atender seu mercado e as firmas ainda não estabelecidas, que possuem o interesse em construir novas plantas para tentar competir com as empresas já instaladas. De outra forma, Kon (1994) considera que a condição de entrada pode ser tratada como a "desvantagem" das firmas com potencial de entrada, em comparação com as firmas já estabelecidas.

Em seu estudo Bain (1956) deu grande importância ao nível de barreiras à entrada e suas contribuições teóricas foram as responsáveis pelo arcabouço que permitiu a construção do paradigma Estrutura-Conduta-Desempenho (E-C-D), que é um instrumento oriundo da Teoria da Organização Industrial, criado para mostrar as variáveis que influenciam o desempenho econômico das empresas (Scherer \& Ross, 1990).

Segundo Possas (1987), os modelos E-C-D buscam avaliar as características da estrutura de mercado para demonstrar sua influência sobre o desempenho das firmas. Dentre as variáveis que determinam a estrutura de uma indústria, encontram-se as barreiras à entrada, que podem influir de forma significativa sobre as chances de um novo concorrente ingressar no mercado, dependendo do tamanho e da intensidade dessas barreiras.

As afirmações a respeito da possibilidade das empresas que pertencem a uma indústria com elevadas barreiras à entrada serem capazes de cobrar preços mais elevados, levaram Bain (1956) a formular a Teoria do Preço-Limite, na qual o preço limite é conceituado como o valor máximo que pode ser cobrado pelo conjunto das empresas incumbentes, sem induzir a entrada de concorrentes (Koutsoyiannis, 1985). Desse modo, é possível verificar que o preço limite possui uma relação direta com as condições de entrada em uma indústria (barreiras à entrada), pois quanto maiores forem estas, maior será aquele, ampliando os ganhos das empresas do setor. Matematicamente tal relação pode ser expressa por meio da Equação (1).

$$
E=\frac{\left(P_{L}-P_{C}\right)}{P_{C}}
$$

Onde: $E$ refere-se as condições ou barreiras à entrada; $P_{L}$ é o preço limite, ou seja, o preço máximo que pode ser cobrado sem atrair novos concorrentes e; $P_{C}$ é o preço que seria cobrado em um mercado competitivo, isto é, com lucros normais. 
Reescrevendo a Equação (1) tem-se que $P_{L}=P_{C}(1+E)$, evidenciando que quanto mais difícil for a entrada de novos concorrentes, maior é o que preço que pode ser cobrado pelas empresas já estabelecidas. Assim, verifica-se que mesmo essa teoria tendo sido desenvolvida inicialmente para tratar do comportamento das empresas em mercados oligopolizados, a literatura industrial admite que a existência de barreiras à entrada em maior ou em menor grau é capaz de influenciar diretamente a concorrência em qualquer tipo de indústria, gerando efeitos sobre seu desempenho competitivo (Scherer \& Ross, 1990).

A esse respeito, o mercado de previdência complementar brasileiro possui duas taxas ou preços que impactam na receita dos fundos incumbentes, isto é, as taxas de carregamento e de administração. A primeira incide sobre os aportes mensais de recursos realizados pelo participante elou pela patrocinadora, bem como, também pode recair sobre o pagamento dos benefícios no período pós-laboral. Já a segunda é uma taxa anual que possui como base de cálculo os ativos acumulados pelo participante ao longo de sua vida (Superintendência de Seguros Privados, 2017).

Um ponto relevante ao preço limite que pode ser praticado pelas EFPC brasileiras, repousa na Resolução no 29, de 31 de agosto de 2009, do antigo Conselho de Gestão da Previdência Complementar (CGPC), atual CNPC, que em seu artigo 6ํㅡㄹ baliza os percentuais máximos para essas duas taxas:

Art. 6ㅇ $\mathrm{O}$ limite anual de recursos destinados pelo conjunto dos planos de benefícios executados pela EFPC de que trata a Lei Complementar no 108, de 2001, para o plano de gestão administrativa, observado o custeio pelo patrocinador, participantes e assistidos, é um entre os seguintes:

I - taxa de administração de até $1 \%$ (um por cento); ou

II - taxa de carregamento de até $9 \%$ (nove por cento)" (CGPC, 2009).

Ou seja, no caso do mercado de previdência complementar fechada, o preço limite não é dado por uma conduta colusiva entre as firmas incumbentes, mas sim, por um ordenamento que emana do órgão regulador, que limita as possibilidades de arrecadação das EFPC para sua manutenção em um determinado patamar.

Por sua vez, para que se possa compreender melhor os elementos presentes na análise do preço limite de Bain (1956) e seu impacto nas EFPC, é preciso tratar de quatro tipos de barreiras à entrada na indústria, a saber: a) necessidade de investimento (capital) inicial elevado; b) diferenciação de produtos; c) vantagens absolutas de custos e; d) economias de escala (Kupfer, 2002).

\subsection{Necessidade de Investimentos Iniciais Elevados}

Quando a entrada de uma empresa em um determinado mercado exige um investimento inicial substancial pode-se afirmar que está caracterizada a existência de uma barreira à entrada (Bain, 1968). Esse tipo de empecilho possui relação direta com a dificuldade encontrada pelos empresários em financiar grandes investimentos, que demandam um volume significativo de recursos para sua implantação inicial (Kupfer, 2002).

Segundo Kupfer (2002), como os grandes investimentos geralmente possuem em sua ampla maioria custos iniciais irrecuperáveis (sunk costs), esses terão influência no comportamento estratégico das firmas e na formação de seu preço de mercado. De maneira mais específica, Almeida (2009) considera que os grandes investimentos a fundo perdido ou irrecuperáveis são os que possibilitam as empresas incumbentes de grande porte cobrarem preços iguais ao seu custo marginal, permitindo que elas tenham vantagens competitivas por conseguirem atender de forma rápida qualquer expansão da demanda.

No caso do mercado de previdência complementar fechada, o investimento inicial para a constituição de um novo fundo de pensão fica a cargo da patrocinadora, que deverá integralizar o montante necessário para a implantação da nova EFPC. A título de exemplo, a Lei no 12.618, de 30 de abril de 2012, em seu Art. 25 , autorizou a União a aportar o valor inicial de $R \$ 50$ milhões para a instituição da Funpresp-Exe; $R \$ 25$ milhões para a Funpresp-Leg e; $R \$ 25$ milhões para a Funpresp-Jud, que são os fundos de pensão, respectivamente, dos poderes executivo, legislativo e judiciário.

Assim, verifica-se que os investimentos iniciais elevados também seriam uma barreira à entrada no mercado de previdência complementar fechada, pois, além de ter que arcar com parcela das contribuições dos participantes e do custeio mensal do fundo, a patrocinadora precisaria aportar um montante inicial significativo para a constituição de uma nova EFPC.

Uma estratégica que muitas empresas têm utilizado para fugir dos investimentos iniciais elevados e que acarreta uma maior concentração desse mercado, refere-se ao patrocínio de planos de benefícios pósemprego em EFPC já existentes, que são customizados segundo o interesse das novas patrocinadoras.

Como incentivo suplementar à essas novas patrocinadoras, o CNPC editou a Resolução $n \div 35$, de 20 de dezembro de 2019, que em seu Art. $4^{\circ}$, parágrafo único, determina que nas entidades multipatrocinadas, a escolha dos representantes das patrocinadoras para os conselhos deliberativo e fiscal deve considerar aquelas que contarem com o maior número de participantes e aquelas que tiverem os maiores recursos garantidores nos planos previdenciários. 
Ou seja, percebe-se que na prática, além da barreira natural referente aos investimentos iniciais elevados, o órgão regulador também garantiu posição privilegiada na governança dos fundos para aquelas empresas que tiverem mais participantes e recursos aplicados, fomentando a formação de poupança previdenciária nas EFPC já constituídas.

\subsection{Diferenciação de Produtos}

A diferenciação de produtos pode atuar como uma barreira à entrada, quando diferenças na qualidade e no design levam a uma certa lealdade dos consumidores com os produtos fabricados pelas empresas já estabelecidas (Maluf, 2002). Em tal situação, a barreira existe, porque as firmas entrantes para se posicionaram de forma competitiva precisam vender seus novos produtos a um preço mais baixo que as incumbentes ou investir um montante considerável em publicidade para divulgar sua marca (Kupfer, 2002).

Para Kon (1994), a estratégia de redução de preços possui a desvantagem de prejudicar a rentabilidade da empresa entrante, sendo difícil de ser mantida no longo prazo. Por sua vez, os gastos elevados com publicidade acarretam no incremento dos custos médios da entrante, o que na prática proporciona uma vantagem absoluta em custos para as empresas já estabelecidas.

De forma complementar, Porter (1985) afirma que a diferenciação de produtos, aliada a redução de custos é uma estratégia genérica utilizada por empresas incumbentes em um determinado mercado para criar barreiras à entrada de novas competidoras, blindando a parcela de mercado das firmas já estabelecidas.

Por essas razões, Bain (1956) considera a diferenciação de produtos como uma das barreiras mais fortes à entrada de novas competidoras no mercado, já que as firmas incumbentes conhecem as preferências dos consumidores e direcionam sua produção para satisfazer os anseios de sua clientela.

No que diz respeito a previdência complementar fechada, as EFPC customizam seus planos previdenciários com o objetivo de atender suas patrocinadoras, que possuem determinadas preferências sobre o desenho do plano e seu regulamento. Atualmente, as empresas que patrocinam planos de benefícios pós-emprego têm demandado dos fundos a redução de riscos atuariais e o combate à eventuais déficits, principalmente, os órgãos e as empresas públicas e de capital misto, que deverão fechar seus atuais planos $\mathrm{BD}$, sujeitos a riscos atuariais, e proporem somente planos na modalidade CD aos seus participantes, conforme determina a resolução CGPAR nำ 25 de 2019 em seus artigos 3ำ 4․

Vale destacar que a mesma resolução em seu artigo 6ํㅜ, parágrafo único, determina que as empresas estatais deverão propor ao seu conselho de administração a transferência de gerenciamento dos planos de benefícios quando não for verificada economicidade na manutenção desses por parte das EFPC que os administrem, o que pode proporcionar uma possibilidade à eventuais EFPC entrantes no mercado, desde que as atuais EFPC não mantenham uma política de diferenciação de produtos, de forma a satisfazer suas patrocinadoras.

\subsection{Vantagens Absolutas de Custos}

As diferenças na estrutura de custos entre firmas incumbentes e entrantes tornam-se barreiras à entrada quando as primeiras possuem vantagens absolutas de custos sobre as últimas (Koutsoyiannis, 1985). $\mathrm{Na}$ visão de Kupfer (2002) essas vantagens seriam decorrentes do acesso exclusivo que as empresas já estabelecidas teriam sobre determinados ativos e recursos, que lhes permitiriam fabricar com escala produtiva similar à de um potencial entrante os mesmos produtos a um custo inferior.

De forma mais específica, Koutsoyiannis (1985) considera que as vantagens de custos das empresas incumbentes residem em três fatos: a) as firmas entrantes necessitariam pagar maiores salários para atrair pessoal especializado; b) as firmas entrantes não possuem disponibilizadas patentes e técnicas avançadas e; c) as firmas incumbentes já possuem uma integração vertical consolidada dentro da cadeia produtiva.

No mercado de previdência complementar fechada, as EFPC já estabelecidas possuem vantagens absolutas de custos em decorrência da oferta restrita de mão de obra qualifica (advogados, atuários, contadores, analistas financeiros, etc.) preparada para lidar com questões regulatórias, de investimentos, de remodelagem de planos, entre outras e; porque a tecnologia utilizada para o controle da gestão patrimonial, previdencial e de investimentos é especifica do setor, não sendo obtida ou customizada por qualquer empresa do ramo de $\mathrm{TI}$ no curto prazo.

\subsection{Economias de Escala}

Em relação às firmas individualmente, seu tamanho é um determinante para a maximização da eficiência (Bain, 1956). De acordo com Besanko et al. (2009), a existência de economias de escala implica na redução dos custos médios nas empresas já estabelecidas, à medida que a produção aumenta. Assim, para que um potencial entrante consiga competir em igualdade com as firmas já estabelecidas, ela terá que iniciar suas operações com uma escala mínima de eficiência (EME) produtiva, que garanta um custo médio semelhante ao das firmas incumbentes. 
A EME refere-se ao tamanho necessário para que uma firma possa minimizar seu custo unitário, de forma que utilize todo seu potencial vinculado as economias de escala (Koutsoyiannis, 1985). Besanko et al. (2009) afirmam que existem três possibilidades básicas que retratam a ocorrência de economias de escala nas empresas, conforme a Figura 1.
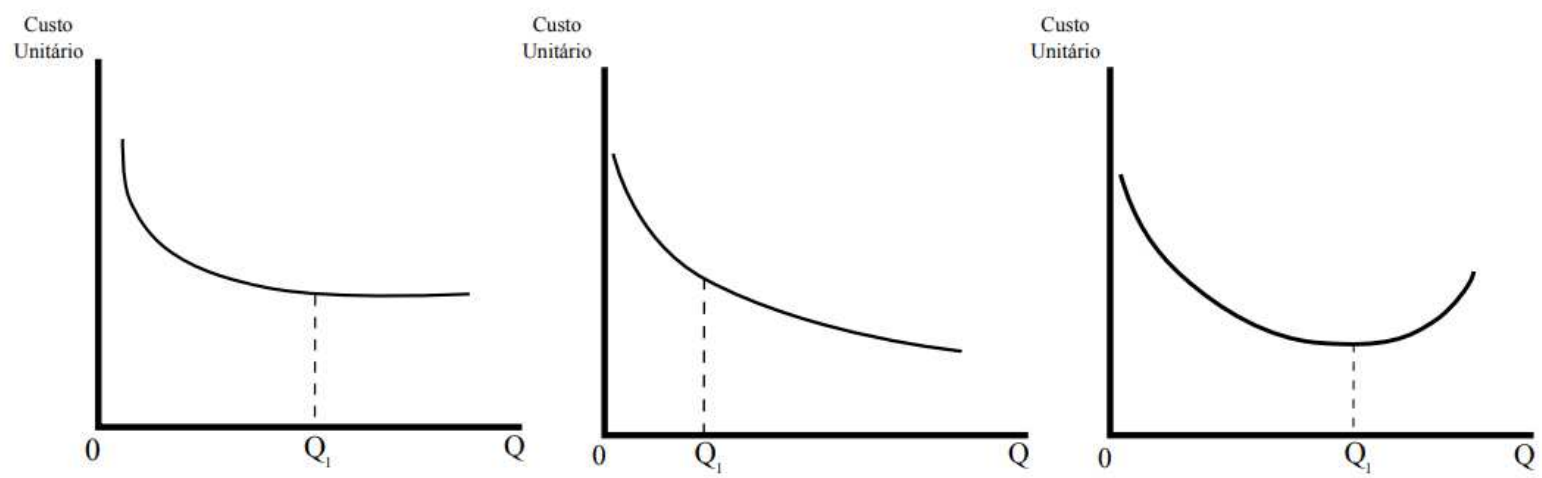

Figura 1: Possibilidades de Economias de Escala

Fonte: Elaborado pelos autores com base em Koutsoyiannis (1985).

A primeira refere-se ao caso da curva de custos na forma de "L", na qual o incremento da produção provocaria uma queda do custo médio até uma quantidade $Q_{1}$, onde, a partir dessa, a firma passaria sempre a operar em seu custo mínimo. Já a segunda diz respeito a curva de custo médio monotonicamente decrescente, na qual as economias de escala vigoram indefinidamente através de toda produção, inexistindo pontos de estrangulamento produtivos. Por fim, a terceira trata da curva de custos na forma de "U", na qual incrementos da produção proporcionariam custos decrescentes até a quantidade $Q_{1}$, onde, a partir dessa, qualquer novo aumento da produção desencadearia em uma trajetória ascendente de custos.

Considerando o mercado das EFPC, a redução em termos unitários das despesas administrativas pode proporcionar maior bem-estar aos participantes ativos, inativos e pensionistas, pois uma parcela maior de recursos será destinada a constituição de ativos previdenciários, vis-à-vis a manutenção das EFPC (Bateman \& Mitchell, 2004).

Por outro lado, quando uma mesma entidade possui um custo inferior em ofertar dois serviços, por exemplo, planos previdenciários e empréstimos consignados, se comparado ao custo desses serviços serem oferecidos individualmente por empresas distintas, as possibilidades dos participantes aumentam, já que esses estarão pagando proporcionalmente menos por uma cesta maior de serviços.

Os dois principais serviços ofertados pelas EFPC são a gestão previdenciária e a gestão dos ativos (investimentos). De forma geral, os estudos econométricos realizados utilizam duas proxies para representar esses serviços em seus modelos, isto é, a quantidade de participantes e o volume total de ativos financeiros de uma EFPC, respectivamente (Bikker, 2017).

Essas duas variáveis utilizadas em uma mesma equação possuem a capacidade de mensurar as economias de escala, se os custos unitários declinarem com o aumento do número de participantes e do volume de ativos das EFPC (Bikker \& De Dreu, 2009). Ou, em termos estatísticos, caso os coeficientes da quantidade de participantes e do volume de ativos sejam inferiores a 1 (um), observa-se a presença de economias de escala nas despesas administrativas das EFPC (Malhotra, Martin \& Mcleod, 2009).

O trabalho de Caswell (1976) foi o primeiro a procurar explicar os determinantes das despesas administrativas nas EFPC fazendo uso de dados em corte cruzado (cross-section), dos planos previdenciários da indústria de construção civil norte americana no biênio 1969-1970. O autor descobriu que o número de participantes era uma variável relevante para explicar as economias de escala das EFPC, obtendo o coeficiente de 0,8 para essa variável.

Mitchell e Andrews (1981) ao aplicarem uma regressão cross-section com dados sobre EFPC patrocinadas por empresas do setor privado dos EUA, para o ano de 1975, verificaram que além do número de participantes, outra importante variável para ocorrência de economias de escala nas EFPC se tratava do total de ativos financeiros dessas entidades. Em seu modelo esses autores encontram os coeficientes de 0,56 e 0,27 para o número de participantes e o total de ativos, respectivamente.

Posteriormente, todos os demais trabalhos sobre a ocorrência de economias de escala nas EFPC passaram a incorporar o número de participantes e o total de ativos como determinantes das despesas administrativas. Por exemplo, Hsin e Mitchell (1997) verificaram a existência de economias de escala em relação à quantidade de participantes (elasticidade de 0,74 ) e ao total de ativos (elasticidade de 0,49 ) para mais de trezentas EFPC de estados e municípios dos EUA.

Bateman e Mitchell (2004) acharam os coeficientes de 0,4 e 0,5 para a quantidade de participantes e o total de ativos das EFPC australianas; Bikker e De Dreu (2009) estimaram os coeficientes de 0,59 e 0,09 para o número de participantes e o total de ativos das EFPC holandesas; Malhotra et al. (2009) encontraram o coeficiente de 0,78 para o total de ativos das EFPC americanas e; Bikker, Steenbeek e Torracchi (2012) 
obtiveram os coeficientes de 0,67 para o número de participantes e 0,19 para o total de ativos das EFPC da Austrália, Canadá, EUA e Holanda, simultaneamente.

No Brasil, Pereira et al. (2013) efetuaram uma regressão múltipla, com dados sobre as despesas administrativas das EFPC para os anos de 2010 e 2011. Como resultados, os pesquisadores verificaram que um aumento de $1 \%$ no número de participantes reflete-se num aumento de $0,05 \%$ nas despesas administrativas. Por sua vez, um incremento de $1 \%$ na variável total de ativos impacta em $0,6 \%$ essas mesmas despesas. Já Pasqualeto et al. (2014) realizaram regressões com dados em painel para o período 2010 2012 considerando duas equações, uma com dados sobre entidades de patrocínio público e outra com dados sobre entidades de patrocínio privado. Para o caso das EFPC públicas, o logaritmo natural do número participantes apresentou coeficiente de 0,078 e o logaritmo natural do total de ativos o coeficiente de 0,62. Com relação as EFPC privadas, os mesmos coeficientes apresentaram os valores de 0,004 e 0,52, respectivamente.

Caetano, Boueri e Sachsida (2015) foram os que elaboraram os modelos mais sofisticados para explicar as despesas administrativas das EFPC brasileiras. Com base em dados para o período 2010 - 2011, os autores utilizaram como variáveis explicativas além do número de participantes e do total de ativos, uma dummy para patrocinadores privados, uma dummy para instituidores, a quantidade de planos das EFPC, a quantidade de patrocinadores das EFPC e a relação de beneficiários sobre participantes ativos. De forma geral, todos os modelos elaborados apresentaram coeficientes com sinais iguais aos esperados pela teoria.

Por fim, Cunha (2018) com base em dados para o período 2010-2014 estimou vários modelos para explicar as despesas administrativas das EFPC brasileiras, procurando controlar um possível efeito político. A hipótese adotada no estudo foi a de que em anos eleitorais, as EFPC públicas incorreriam em maiores gastos para apoiar candidatos alinhados com o governo vigente a época. Apesar de todos os modelos terem apresentados economias de escala para as principais variáveis explicativas, isto é, o total de ativos financeiros e o total de participantes, nenhum deles confirmou a hipótese do efeito político para as EFPC públicas.

Um ponto em comum nos trabalhos citados anteriormente é que todos buscaram evidências de economias de escala em EFPC adotando modelos para a curva de custo médio monotonicamente decrescente. Até onde se tem conhecimento, apenas o estudo de Bikker (2017) procurou utilizar diferentes modelos para estimar funções custo na forma de "U", para as despesas administrativas dos fundos de pensão holandeses considerando o período 1992-2009.

Destarte, verifica-se que existe uma lacuna na literatura quanto a mais estudos que trabalhem a questão de outras formas para a função custo, que não a monotonicamente decrescente, para as despesas administrativas das EFPC no Brasil e no mundo. Sendo assim, o objetivo da presente pesquisa é investigar se existe um tamanho ótimo para a operação das EFPC brasileiras, com base em suas despesas administrativas. Em outras palavras, pretende-se verificar se os fundos de pensão brasileiros gozariam de economias de escala até um determinado ponto, onde, a partir do qual, a complexidade das grandes estruturas passaria a provocar deseconomias de escala, o que equivale a estimar funções custo no formato de "U". Para tanto, o estudo de Bikker (2017) será replicado, sendo observadas as peculiaridades dos fundos de pensão brasileiros.

\section{Base de dados, Metodologia e Modelo Empírico}

Todos os dados foram coletados no site da PREVIC, órgão supervisor do setor, através dos seguintes instrumentos: séries de estudos "Divulgação das Despesas Administrativas ํo 7 e ํo 8"; balancetes consolidados das EFPC e; balancetes individuais de cada um dos planos dos fundos de pensão. Tendo em vista que a PREVIC divulgou as séries de estudos das despesas administrativas somente para o período 2010-2014 e para o período 2017-2018, deixando de fora os anos de 2015 e 2016, optou-se por utilizar somente o período mais recente no estudo. Além disso, vale destacar que todos os valores monetários foram corrigidos a preços de 2018 pelo INPC, que é o índice mais utilizado para corrigir os benefícios pós-emprego pagos pelos fundos de pensão.

Como os dados coletados combinam observações de corte transversal e séries de tempo, foi adotada a metodologia da econometria de dados em painel, que considera explicitamente a questão da heterogeneidade, com as diferenças individuais entre as unidades estudadas sendo formalmente capturadas (Gujarati \& Porter, 2011).

É importante frisar que não existiam na base de dados informações completas sobre todas as EFPC para o período investigado, o que fez com que os modelos de dados em painel construídos fossem não balanceados. Todavia, de acordo com Baltagi (1995) tal situação não compromete a qualidade das estimações. Sendo assim, de um conjunto total de 600 observações ou 304 EFPC, a amostra final contou com 455 observações ou 231 EFPC que possuíam dados para todas as variáveis utilizadas no estudo.

$\mathrm{Na}$ estimação da função de custo ótimo das EFPC na forma de "U", foram adotadas as quatro equações propostas em Bikker (2017). A primeira refere-se à função custo translog como uma expansão de Taylor de segunda ordem para o total de participantes das EFPC, onde as economias de escala seriam verificadas para um coeficiente $\beta_{1}<1$ e a curva de custo médio teria a formato de "U" se o coeficiente de $\beta_{2}>0$. A Equação (2) retrata a função custo translog para total de participantes como o principal insumo. 
$\ln D P_{i t}=\beta_{0}+\beta_{1}\left(\operatorname{lnPop}_{i t}\right)+\beta_{2}\left(\operatorname{lnPop}_{i t}-\overline{\operatorname{lnPop}}_{i t}\right)^{2}+\beta_{3} \ln Q \operatorname{Plan}_{i t}+\beta_{4}$ Matu $_{i t}+\beta_{5}$ PerCD $_{i t}+\beta_{6}$ Fed $_{i t}+$ $\beta_{7}$ Est $_{i t}+\beta_{8}$ Mun $_{i t}+\beta_{9}$ Inst $_{i t}+\beta_{10}$ Terc $_{i t}+\beta_{11} R S B_{i t}+\varepsilon_{i t}$

em que: $i$ refere-se a EFPC e $t$ ao tempo. A variável dependente $\ln D P$, diz respeito ao logaritmo natural das despesas administrativas previdenciais e as variáveis explanatórias são: o logaritmo natural do total de participantes $(\ln P o p)$ e 0 logaritmo natural do total de participantes centrado na média ao quadrado $(\ln P o p-\overline{\ln P o p})^{2}$. As demais variáveis de controle são: o logaritmo natural da quantidade de planos de benefícios InQPlan; a maturidade da EFPC Matu; o percentual de planos CD em relação ao total de planos PerCD; dummy para EFPC federais Fed; dummy para EFPC estaduais Est; dummy para EFPC municipais Mun; dummy para EFPC criadas por instituidores Inst; percentual de despesas com serviços de terceiros sobre as despesas totais (terceirização) Terc e; dummy para EFPC localizada no Rio de Janeiro, São Paulo ou Brasília RSB.

Para o coeficiente do logaritmo natural da quantidade de planos é esperado um valor positivo e menor que a unidade, indicando que a oferta de um novo plano incrementa as despesas previdenciais menos que proporcionalmente (Caetano et al., 2015). Por sua vez, com relação ao coeficiente da maturidade da EFPC, que é dado pelo quociente do total de benefícios a conceder pelo total de benefícios concedidos, é esperado sinal positivo, pois entende-se que quanto mais pessoas estiverem em gozo de benefícios na EFPC, maiores serão os gastos previdenciais com atendimento, comunicação e demandas de cunho atuarial e judicial.

Já para o percentual de planos CD geridos pelas EFPC, acredita-se que seu coeficiente deva ser negativo e estatisticamente significativo. Tal hipótese decorre do fato dos planos CD serem livres de riscos, 0 que reduz as despesas com serviços atuariais e advocatícios conforme aumenta a quantidade desses planos nas carteiras dos fundos, em detrimento dos planos BD e CV.

No que diz respeito ao tipo de patrocínio das EFPC, adotou-se o patrocínio privado como categoria base. Assim, segundo Caetano et al. (2015) e Cunha (2018) é esperado que as EFPC públicas (federais, estaduais e municipais) tenham maiores despesas administrativas. Por outro lado, espera-se que as EFPC mantidas por instituidores tenham menores despesas administrativas que as EFPC privadas, principalmente, porque as primeiras não possuem o auxílio de patrocinadoras, sendo mantidas exclusivamente por seus participantes e pelos seus investimentos, o que exige um elevado nível de disciplina administrativa e financeira para que sejam rentáveis.

Considerando o coeficiente da variável de terceirização é esperado um sinal negativo, evidenciando que quanto maior for a troca das despesas com a manutenção do quadro de pessoal próprio, por maiores gastos com serviços de terceiros, maior será o potencial de redução das despesas administrativas (Bikker \& De Dreu, 2009; Cunha, 2018). Por fim, de acordo com Cunha (2018), deve-se esperar um coeficiente positivo para a dummy das EFPC localizadas no Rio de Janeiro, São Paulo ou Brasília, pois o custo de vida nessas metrópoles é superior aos das demais localidades brasileiras.

Conforme recomendado por Bikker (2017), também foram testadas mais três alternativas para a função custo na forma de "U": a função de Laurent irrestrita (FLI), que é semelhante a translog, mas com dois termos adicionais para o total de participantes, ou seja, $1 /(\ln P o p)$ e $1 /(\ln P o p)^{2}$, em que, segundo Shaffer (1998), para que a forma de "U" se mantenha, é preciso que os coeficientes dessas duas novas variáveis sejam positivos e próximos em magnitude de $\beta_{2}$; uma versão simplificada da FLI, com somente $1 /(\ln P o p)$ como termo adicional e; a função custo Cobb-Douglas, que troca o coeficiente $\beta_{2}$ da equação translog original, isto é, $\left(\operatorname{lnPop}_{i t}-\overline{\operatorname{lnPop}}_{i t}\right)^{2}$, por $1 /$ Pop (um dividido pela população total). Diferentemente das demais, essa última equação retrata a forma de "U" se $\beta_{1}>\beta_{2}$, por sua vez, se $\beta_{1}>1$ e $\beta_{2}>0$, a curva de custo médio passa a se comportar em declínio monotônico. Por fim, caso $\beta_{1}<1$ a curva de custo médio terá a forma de "L".

De acordo com Bikker (2017) a regra de decisão para escolher o melhor entre os quatro modelos repousa em dois estágios. No primeiro deve ser avaliada a estatística de inflação da variância (VIF) para identificar uma eventual multicolinearidade no modelo. Caso inexista tal problema, ou seja, um VIF $<10$ devese passar para o segundo estágio, que reside na análise do critério Akaike. Para esse último, quanto menor for o valor obtido, melhor é o modelo.

A segunda estimação do custo ótimo das EFPC na forma de "U”, diz respeito à função custo translog como uma expansão de Taylor de segunda ordem tendo como insumo o total de ativos financeiros, com as economias de escala sendo identificadas para o coeficiente $\beta_{1}<1$ e a curva de custo médio com formato de "U" se o coeficiente de $\beta_{2}>0$. A Equação (3) retrata a função custo translog para total de ativos financeiros como o principal insumo.

$\operatorname{lnDI}_{i t}=\beta_{0}+\beta_{1}\left(\operatorname{lnAtivo}_{i t}\right)+\beta_{2}\left(\operatorname{lnAtivo}_{i t}-\overline{\ln A t \imath v o}_{i t}\right)^{2}+\beta_{3} \ln Q P \operatorname{lan}_{i t}+\beta_{4}$ Solv $_{i t}+\beta_{5}$ PerCD $_{i t}+\beta_{6}$ Fed $_{i t}+$ $\beta_{7}$ Est $_{i t}+\beta_{8}$ Mun $_{i t}+\beta_{9}$ Inst $_{i t}+\beta_{10} \operatorname{Terc}_{i t}+\beta_{11} R S B_{i t}+\varepsilon_{i t}$

em que: $i$ refere-se a EFPC e $t$ ao tempo. A variável dependente InDI, diz respeito ao logaritmo natural das despesas administrativas com investimentos e as variáveis explanatórias são: o logaritmo natural do total de ativos financeiros (lnAtivo) e o logaritmo natural do total de ativos financeiros centrado na média ao quadrado $(\ln A t i v o-\overline{\operatorname{lnAt} t v o})^{2}$. As 
demais variáveis de controle são as mesmas da Equação (2), com exceção de Matu, que foi substituída pela variável solvência Solv.

Nessa equação, a expectativa quanto aos sinais da maior parte dos coeficientes são as mesmas da Equação (2). Somente a variável solvência que deve ser explicada. Como essa última é formada pelo quociente das provisões matemáticas pelo patrimônio de cobertura das EFPC, espera-se um sinal negativo, indicando que quanto mais solventes forem as EFPC, menores serão suas despesas com investimentos, o que indicaria eficiência administrativa na gestão dos recursos.

Além disso, vale destacar que foram estimadas outras três alternativas para a função custo do total de ativos financeiros, ou seja, a FLI, com os termos adicionais à função translog $1 /(\ln$ Ativo $)$ e $1 /(\ln \text { Ativo })^{2}$; a versão simplificada da $\mathrm{FLI}$, com somente $1 /(\ln A t i v o)$ como termo adicional e; a função custo CobbDouglas, que substitui o termo (lnAtivo $-\overline{\ln A t \text { tivo }})^{2}$ por $1 /$ Ativo (um dividido pelo total de ativos financeiros). A Figura 2 sintetiza todas as variáveis explicativas utilizadas nas equações, seus sinais esperados e 0 referencial empírico.

\begin{tabular}{|c|c|c|}
\hline Variável & $\begin{array}{c}\text { Sinal } \\
\text { Esperado }\end{array}$ & Referencial Empírico \\
\hline$(\ln P o p)$ & 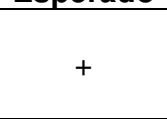 & $\begin{array}{l}\text { Caswell (1976); Mitchell e Andrews (1981); Hsin e Mitchell (1997); Bateman e } \\
\text { Mitchell (2004); Malhotra et al. (2009); Bikker, Steenbeek e Torracchi (2012); } \\
\text { Pasqualeto et al. (2014); Caetano et al. (2015) e; Cunha (2018) }\end{array}$ \\
\hline$\left(\operatorname{lnPop}_{i t}-\overline{\operatorname{lnPop}}_{i t}\right)^{2}$ & + & Bikker (2017) \\
\hline $1 /(\ln P o p)$ & + & Bikker (2017) \\
\hline $1 /(\ln P o p)^{2}$ & + & Bikker (2017) \\
\hline $1 /(P o p)$ & + & Bikker (2017) \\
\hline$(\ln A t i v o)$ & + & $\begin{array}{c}\text { Mitchell e Andrews (1981); Hsin e Mitchell (1997); Bateman e Mitchell (2004); } \\
\text { Malhotra et al. (2009); Bikker, Steenbeek e Torracchi (2012); Pasqualeto et al. } \\
\text { (2014); Caetano et al. (2015) e; Cunha (2018) }\end{array}$ \\
\hline$(\ln A t i v o-\overline{\ln A t \imath v o})^{2}$ & + & Bikker (2017) \\
\hline $1 /(\ln$ Ativo $)$ & + & Bikker (2017) \\
\hline $1 /(\ln A \text { tivo })^{2}$ & + & Bikker (2017) \\
\hline $1 /$ Ativo & + & Bikker (2017) \\
\hline lnQPlan & + & Pasqualeto et al. (2014); Caetano et al. (2015) e; Cunha (2018) \\
\hline Matu & + & Teixeira, Santos e Macedo (2020) \\
\hline PerCD & - & Bikker e De Dreu (2009); Teixeira, Santos e Macedo (2020) \\
\hline Fed & + & Bikker, Steenbeek e Torracchi (2012); Cunha (2018) \\
\hline Est & + & Bikker, Steenbeek e Torracchi (2012); Cunha (2018) \\
\hline Mun & + & Bikker, Steenbeek e Torracchi (2012) \\
\hline Inst & - & Caetano et al. (2015) e; Cunha (2018) \\
\hline Terc & - & $\begin{array}{l}\text { Bateman e Mitchell (2004); Bikker e De Dreu (2009); Bikker (2017); Cunha } \\
\text { (2018) }\end{array}$ \\
\hline$R S B$ & + & Cunha (2018) \\
\hline Solv & - & Teixeira, Santos e Macedo (2020) \\
\hline
\end{tabular}

Figura 2: Resumo das Variáveis Explicativas Utilizadas

Fonte: Elaboração dos autores.

\section{Análise dos Resultados}

A Equação (2) e suas derivações foram estimadas para investigar se existe um tamanho ótimo para as EFPC brasileiras, de modo que suas despesas administrativas com a gestão previdencial sejam minimizadas, isto é, buscou-se verificar se tais despesas possuem um comportamento na forma de "U", conforme o total de participantes vinculados à essas entidades aumenta. A Tabela 2 sintetiza os resultados.

De início é possível notar que todos os modelos estimados apresentaram distribuição normal e variância constante nos resíduos (homocedasticidade). Além disso, a estatística $\mathrm{F}$ revelou que as variáveis independentes em conjunto são significativas, com o $\mathrm{R}^{2}$ ajustado evidenciando um poder explicativo de, pelo menos, $65,7 \%$.

Para escolha do melhor modelo foi utilizado o critério proposto por Bikker (2017). Assim, como o modelo FLI apresentou uma VIF média superior a 10, ele foi descartado no primeiro estágio de avaliação por apresentar o problema da multicolinearidade. Posteriormente, o menor valor para o critério Akaike foi obtido pelo modelo translog, sendo esse o melhor para explicar as despesas administrativas com a gestão previdencial das EFPC.

Como é possível verificar pelo modelo translog, o mercado das EFPC brasileiras efetivamente apresenta uma quantidade ótima de participantes que minimiza as despesas com a gestão previdencial, pois os coeficientes $\beta_{1}<1$ e $\beta_{2}>0$ apresentaram as magnitudes e os sinais esperados, sendo ambos significantes a $1 \%$. 
Tabela 2:

Modelos Estimados para as Despesas Administrativas Previdenciais

\begin{tabular}{|c|c|c|c|c|}
\hline Variável & Translog & $\begin{array}{c}\text { Função de } \\
\text { Laurent Irrestrita } \\
\text { (FLI) }\end{array}$ & $\begin{array}{c}\text { Versão } \\
\text { Simplificada } \\
\text { FLI }\end{array}$ & $\begin{array}{c}\text { Função Cobb- } \\
\text { Douglas }\end{array}$ \\
\hline LnPop & $0,4366^{\star \star *}$ & $0,7964^{\star \star \star}$ & $0,4422^{\star * *}$ & $0,4260^{\star * *}$ \\
\hline LnPop² (desvio média) & $0,0462^{* * *}$ & $-0,0095$ & $0,0431^{* * *}$ & - \\
\hline $1 /(\mathrm{Pop})$ & - & - & - & $6,3752^{* * *}$ \\
\hline 1/(LnPop) & - & $26,1519^{* * *}$ & 0,3112 & - \\
\hline $1 /\left(\right.$ LnPop $^{2}$ & - & $-13,8307^{* * *}$ & - & - \\
\hline LnQPlan & $0,2799^{* * *}$ & $0,2777^{\star \star \star}$ & $0,2814^{\star * *}$ & $0,3219^{* \star *}$ \\
\hline Maturidade & 0,0012 & 0,0014 & 0,0012 & 0,0016 \\
\hline Percentual Planos CD & $-0,1434$ & $-0,1666$ & $-0,1442$ & $-0,1744^{*}$ \\
\hline Federal & $0,7945^{\star * *}$ & $0,8077^{* * *}$ & $0,7971^{* * *}$ & $0,8348^{* * *}$ \\
\hline Estadual & $0,2942^{* * *}$ & $0,2972^{\star * *}$ & $0,2922^{\star * *}$ & $0,2822^{\star *}$ \\
\hline Municipal & $-0,6175^{*}$ & $-0,5601$ & $-0,6133^{\star}$ & $-0,5903$ \\
\hline Instituidor & $-0,4897^{\star * *}$ & $-0,4719^{\star \star \star}$ & $-0,4870^{\star \star \star}$ & $-0,4311^{* *}$ \\
\hline Terceirização & $-1,1206^{\star * *}$ & $-1,1546^{\star \star \star}$ & $-1,1203^{\star \star *}$ & $-1,1348^{\star * *}$ \\
\hline EFPC no RJ, SP ou DF & $0,1812^{* *}$ & $0,1853^{\star *}$ & $0,1812^{\star \star}$ & $0,1934^{\star *}$ \\
\hline Constante & $11,1762^{\star \star *}$ & $5,2810^{\star *}$ & $11,0952^{\star * *}$ & $11,3223^{* * *}$ \\
\hline № Observações & 455 & 455 & 455 & 455 \\
\hline Estatística F & 83,61 & 72,17 & 76,50 & 80,06 \\
\hline $\mathrm{R}^{2}$ ajustado (\%) & 66,68 & 67,08 & 66,62 & 65,70 \\
\hline VIF (média) & 1,36 & 51,61 & 1,69 & 1,35 \\
\hline Critério Akaike & 992,12 & 988,56 & 993,99 & 1005,33 \\
\hline Swekness-Kurtosis $\left(x^{2}\right)$ & 2,57 & 1,64 & 2,31 & 5,20 \\
\hline Breusch-Pagan $\left(x^{2}\right)$ & 0,10 & 0,00 & 0,12 & 0,84 \\
\hline Derivada Primeira & $\begin{array}{c}0,437+ \\
2^{*} 0,046^{*}(\mathrm{LnPop}- \\
\text { média LnPop) }\end{array}$ & $\begin{array}{c}0,796+2^{*}- \\
0,0095^{*}(\text { LnPop- } \\
\text { média LnPop) }- \\
26,152 /(\text { LnPop })^{2} \\
+2^{*} 13,831 /(\text { LnPop })^{3}\end{array}$ & $\begin{array}{c}0,442+ \\
2^{\star} 0,043^{*} \text { (InPop- } \\
\text { média LnPop) - } \\
0,311 /(\text { LnPop })^{2}\end{array}$ & $\begin{array}{c}0,426- \\
6,375 / \text { Pop }\end{array}$ \\
\hline $\begin{array}{l}\text { Tamanho Ótimo } \\
\text { (em participantes) }\end{array}$ & 2.094 .243 & 1.031.463.723.342 & 3.109 .586 & Sem Ótimo \\
\hline Elasticidade Custo & 0,437 & 0,476 & 0,438 & 0,425 \\
\hline
\end{tabular}

***significante a $1 \% ;{ }^{\star \star}$ significante a $5 \%$ e; * significante a $10 \%$.

Fonte: Elaborado pelos autores.

As economias de escala capturadas pelo coeficiente $\beta_{1}$ foram superiores a $56 \%(1-0,4366)$ e ao aplicar a derivada primeira na função translog em relação a população e igualar a um, obtêm-se a quantidade ótima de participantes das EFPC brasileiras, que foi de 2.094.243 pessoas para o período 2017-2018. Esse resultado sugere que a implantação de mais barreiras à entrada e a concentração das EFPC traria benefícios a seus participantes em termos de redução de custos, principalmente, considerando que o maior fundo de pensão brasileiro em 2018 tinha aproximadamente pouco mais de 195 mil pessoas.

O coeficiente do logaritmo natural da quantidade de planos foi positivo e significativo, assim como em Cunha (2018), indicando que um incremento de $1 \%$ na oferta de planos provoca um aumento da ordem de $0,28 \%$ nas despesas administrativas previdenciais, o que reforça as economias de escala.

No que diz respeito as dummies para as EFPC com patrocínio público federal e estadual, observouse coeficientes positivos e significativos, conforme já esperado. Ou seja, esse resultado corrobora que os fundos de pensão com patrocínio privado tendem a ser mais eficientes que esses dois tipos de fundos públicos. Todavia, efeito oposto ocorreu com as EFPC públicas municipais e as instituídas, evidenciando que o detalhamento do tipo de patrocínio dos fundos é importante para não gerar conclusões espúrias. Os trabalhos de Pereira et al. (2013) e Caetano et al. (2015) ao analisarem de forma agregada as EFPC de patrocínio público versus as EFPC com patrocínio privado, concluíram que essas últimas eram mais econômicas que as primeiras, o que não é necessariamente verdade, já que as EFPC públicas municipais se mostraram mais eficientes que as EFPC privadas.

Os coeficientes das variáveis terceirização e localização também se mostraram significativos e com os sinais esperados. Enquanto o primeiro foi negativo como em Bikker e De Dreu (2009) e Cunha (2018), confirmando que maiores gastos com serviços de terceiros levam a menores despesas administrativas, 0 segundo foi positivo, evidenciando que o custo de vida nas grandes metrópoles Rio de Janeiro, São Paulo e Brasília, contribui para aumentar as despesas dos fundos sediados nessas cidades.

Por fim, é interessante comentar que apesar dos coeficientes da maturidade e do percentual de planos CD terem exibido os sinais esperados, nenhum deles foi significante para explicar as despesas administrativas previdenciais das EFPC.

Já os modelos das despesas administrativas com investimentos desvelaram de início o problema da não normalidade e da heterocedasticidade nos resíduos, sendo necessária a exclusão de 71 observações 
com comportamento atípico nos três primeiros modelos (translog, FLI e versão simplificada FLI) e 72 observações no último (Cobb-Douglas). Após essas eliminações, a normalidade foi estabelecida em todos os modelos, com a heterocedasticidade também sendo corrida para a função translog. Para os demais modelos, o problema da heterocedasticidade foi acomodado pela correção de erros-padrão robustos de Huber-White. A Tabela 3 resume os resultados.

De maneira geral é possível observar que o $\mathrm{R}^{2}$ ajustado foi superior a $84,9 \%$ em todos os modelos e a estatística $F$ rejeitou a hipótese nula de que todos os coeficientes são iguais a zero para as variáveis explicativas.

Tabela 3:

Modelos Estimados para as Despesas Administrativas com Investimentos

\begin{tabular}{|c|c|c|c|c|}
\hline Variável & Translog & Função de Laurent Irrestrita (FLI) & Versão Simplificada FLI & $\begin{array}{l}\text { Função } \\
\text { Cobb- } \\
\text { Douglas }\end{array}$ \\
\hline $\begin{array}{l}\text { LnAtivo } \\
\text { LnAtivo }^{2}\end{array}$ & $0,5820^{\star \star \star}$ & 7,7923 & $2,1433^{\star *}$ & $0,6401^{* * *}$ \\
\hline $\begin{array}{l}\text { (desvio } \\
\text { média) }\end{array}$ & $0,0259^{\star \star \star}$ & $-0,1839$ & $-0,0470$ & - \\
\hline 1/(Ativo) & - & - & - & $\underset{*}{1,29 \mathrm{E}}+07^{* *}$ \\
\hline 1/(LnAtivo) & - & $5.302,94$ & $638,7343^{*}$ & - \\
\hline $1 /(\text { LnAtivo })^{2}$ & - & $-23.460,03$ & - & - \\
\hline LnQPlan & $0,2831^{* \star *}$ & $0,2665^{\star * \star}$ & $0,2696^{\star * \star}$ & $0,2832^{* * *}$ \\
\hline $\begin{array}{l}\text { Solvência } \\
\text { Percentual }\end{array}$ & $-0,0674$ & $-0,0641$ & $-0,0642$ & $-0,0661$ \\
\hline Planos CD & $-0,1597^{\star}$ & $-0,1907^{\star}$ & $-0,1955^{\star *}$ & $-0,2204^{\star *}$ \\
\hline Federal & $0,6004^{\star \star *}$ & $0,6071^{* * *}$ & $0,6073^{* \star *}$ & $0,6356^{* * *}$ \\
\hline Estadual & $0,2480^{* * *}$ & $0,2862^{\star * *}$ & $0,2878^{* * *}$ & $0,2621^{* * *}$ \\
\hline Municipal & $-0,2554$ & $-0,1903$ & $-0,1868$ & $-0,1806$ \\
\hline Instituidor & $-0,2966^{\star *}$ & $-0,2785$ & $-0,2645$ & $-0,2251$ \\
\hline $\begin{array}{l}\text { Terceiriza- } \\
\text { ção } \\
\text { EFPC no }\end{array}$ & $-0,2761^{\star *}$ & $-0,2167^{\star}$ & $-0,2187^{*}$ & $-0,2344^{*}$ \\
\hline $\begin{array}{l}\text { RJ, SP ou } \\
\text { DF }\end{array}$ & $0,1717^{\star \star *}$ & $0,1708^{\star *}$ & $0,1735^{\star *}$ & $0,1819^{\star * *}$ \\
\hline Constante & $2,2088^{\star * *}$ & $-348,48$ & $-60,9765$ & $1,0122^{*}$ \\
\hline $\begin{array}{l}\text { № Obser- } \\
\text { vações } \\
\text { Estatística }\end{array}$ & 384 & 384 & 384 & 383 \\
\hline & 197,41 & 290,85 & 245,21 & 195,71 \\
\hline $\begin{array}{l}\mathrm{R}^{2} \text { ajustado } \\
(\%) \\
\text { VIF }\end{array}$ & 84,94 & 85,57 & 85,57 & 85,21 \\
\hline $\begin{array}{l}\text { (média) } \\
\text { Critério }\end{array}$ & 1,36 & $3,02 E+05$ & 589,43 & 1,46 \\
\hline $\begin{array}{l}\text { Akaike } \\
\text { Swekness- }\end{array}$ & 620,01 & 620,68 & 620,86 & 622,22 \\
\hline $\begin{array}{l}\text { Kurtosis } \\
\left(x^{2}\right) \\
\text { Breusch- }\end{array}$ & 1,90 & 1,91 & 1,61 & 0,63 \\
\hline Pagan $\left(x^{2}\right)$ & 5,13 & 7,94 & 8,43 & 7,49 \\
\hline $\begin{array}{l}\text { Derivada } \\
\text { Primeira }\end{array}$ & $\begin{array}{c}0,528+ \\
2^{*} 0,026^{*}(\text { LnAtivo- } \\
\text { média LnAtivo) }\end{array}$ & $\begin{array}{c}7,792+2^{*}-0,184^{*}(\text { LnAtivo-média } \\
\text { LnAtivo })-5.303 /(\text { LnAtivo })^{2}+ \\
23.460 /(\text { LnAtivo })^{3}\end{array}$ & $\begin{array}{c}2,143+2^{\star}-0,047^{\star}(\text { LnAtivo- } \\
\text { média LnAtivo })- \\
639 /(\text { LnAtivo })^{2}\end{array}$ & $\begin{array}{l}0,6401- \\
1,29 E+07 / A \\
\text { tivo }\end{array}$ \\
\hline Tamanho & & & & \\
\hline $\begin{array}{l}\text { Ótimo } \\
\text { (em Total } \\
\text { de Ativos) }\end{array}$ & $R \$ 2.767 \mathrm{bi}$ & $\mathrm{R} \$ 88.519 .565 \mathrm{bi}$ & $\mathrm{R} \$ 152.777 \mathrm{bi}$ & Sem Ótimo \\
\hline $\begin{array}{l}\text { Elasticidad } \\
\text { e Custo }\end{array}$ & 0,528 & $-2,048$ & 0,633 & 0,625 \\
\hline
\end{tabular}

***significante a $1 \% ;{ }^{* \star}$ significante a $5 \%$ e; *significante a $10 \%$.

Nota: Como a hipótese nula de homocedasticidade foi rejeitada a $1 \%$ de significância para os modelos derivados das funções FLI, versão simplificada FLI e Cobb-Douglas, seus resultados foram apresentados já considerando a correção de erros-padrão robustos de Huber-White.

Fonte: Elaborado pelos autores.

Como a função translog apresentou uma estatística $\mathrm{VIF}<10$ associada ao menor valor para o critério Akaike dentre todos os modelos, pode-se argumentar que mais uma vez, essa é a modelagem mais adequada segundo o critério proposto por Bikker (2017), para explicar as despesas administrativas com investimentos no mercado brasileiro de previdência complementar fechada. 
Os coeficientes $\beta_{1}<1$ e $\beta_{2}>0$ para o total de ativos e sua versão quadrática apresentaram as magnitudes e os sinais esperados, sendo ambos significativos a $1 \%$, permitindo concluir que existe uma quantidade ótima de ativos financeiros que minimiza as despesas com investimentos das EFPC. Enquanto $o$ coeficiente $\beta_{1}$ do logaritmo natural do total de ativos exibiu economias de escala da ordem de $41,80 \%$ ( 1 0,5820 ), o cálculo da derivada primeira das despesas administrativas em relação aos ativos financeiros revelou que os fundos de pensão brasileiros atingiriam o ponto de mínimo da curva "U" com aproximadamente $\mathrm{R} \$ 2.767$ bilhões. A esse respeito, mais uma vez é possível verificar que as EFPC brasileiras se encontram distantes dessa marca, pois o maior fundo de pensão brasileiro tinha em sua carteira um valor da ordem de $\mathrm{R} \$ 205$ bilhões em ativos no ano de 2018.

Com relação ao coeficiente da solvência, que é uma variável de cunho financeiro pôde-se inferir que seu sinal foi negativo, conforme esperado. Todavia, a mesma não se mostrou estatisticamente significante para explicar as despesas administrativas com os investimentos.

Por sua vez, o coeficiente da variável percentual de planos CD foi negativo e significativo a $10 \%$, evidenciando que entidades com mais planos CD em suas carteiras possuem menores despesas administrativas com investimentos. Isso confirma que o gerenciamento dos planos CD é mais barato que os planos $\mathrm{BD}$ e CV, que possuem riscos atuariais e envolvem elevados gastos com consultoria atuarial para acompanhamento e reestruturação de déficits, conforme constataram Teixeira, Santos e Macedo (2020).

\section{Considerações Finais}

O objetivo da presente pesquisa foi investigar a existência de um tamanho ótimo para a operação das Entidades Fechadas de Previdência Complementar (EFPC) brasileiras, com base em suas despesas administrativas. Em outras palavras, pretendeu-se verificar se os fundos de pensão brasileiros gozariam de economias de escala até um determinado ponto, a partir do qual, a complexidade das grandes estruturas passaria a provocar deseconomias de escala.

Para tanto foi utilizado como pano de fundo a teoria clássica da organização industrial, com enfoque nas barreiras à entrada de novas firmas, principalmente, pelo fato de as economias de escala existentes proporcionarem grandes vantagens às EFPC incumbentes em termos de minimização de custos, beneficiando diretamente seus participantes.

Os resultados mostraram que o mercado brasileiro de previdência complementar fechada possui um ponto ótimo de operação, que minimiza as despesas administrativas de cunho previdencial e com investimentos. Considerando as despesas administrativas previdenciais foi verificado que o número ideal de participantes das EFPC seria em torno de 2,1 milhões. Por sua vez, para as despesas administrativas com investimentos, pôde-se constatar que o volume alvo de ativos financeiros seria da ordem de $R \$ 2,8$ trilhões.

Tendo em vista que em 2018 a maior EFPC brasileira tinha 195 mil participantes e $R \$ 205$ bilhões em ativos, observa-se que essa entidade poderia crescer mais de dez vezes antes de atingir seu ponto de ótimo. Isso significa que a concentração do mercado dos fundos de pensão, em poucas EFPC, traria enormes benefícios para seus participantes ativos e inativos em termos de custos, o que justifica ações do CNPC no sentido de restringir a entrada de novos fundos, como já consta na Resolução no 35 de 2019, em seu Art. 6으, inciso III, que sujeita a criação de uma nova EFPC a um número mínimo de 10 mil participantes.

A esse respeito, Bikker (2017) afirma que a fusão de fundos menores seria benéfica para o mercado, pois os ganhos de escala capturados por uma estrutura maior seriam repassados para seus participantes na forma de ampliação da poupança previdenciária, redundando na concessão de melhores benefícios pósemprego.

Como sugestões para trabalhos futuros propõe-se que o cálculo do tamanho ótimo para os fundos de pensão brasileiros seja efetuado segundo a classificação do total de ativos financeiros em cinco grupos distintos (A, B, C, D e E), de acordo com o apresentado pela PREVIC em suas "séries de estudos", que tratam das despesas administrativas em EFPC. Desse modo, seria possível analisar se as economias de escala diferem de forma significativa entre os grupos, em que é esperado que os menores fundos desfrutem de maiores economias de escala vis-à-vis aos maiores.

\section{Referências}

Almeida, E. S (2009). O mercado de televisão a cabo no Brasil. Ensaios FEE, 30(1), 257-280. Recuperado em 12 junho, 2019, de https://revistas.fee.tche.br/index.php/ensaios/article/view/2258

Ambachtsheer, K. (2010). Future directions in measuring the financial performance of pension funds: a roundtable discussion, in: R. Hinz, R. Heinz, P. Antolin, J. Yermo (eds.), Evaluating the Financial Performance of Pension Funds, Washington, DC: World Bank.

Associação Brasileira das Entidades Fechadas de Previdência Complementar (ABRAPP). Consolidado Estatístico. Recuperado em 12 junho, 2019, de http://www.abrapp.org.br/Consolidados/Consolidado\%20Estat\%C3\%ADstico 12.2018.pdf 
Associação Nacional dos Contabilistas das Entidades de Previdência (ANCEP). Indicadores. Recuperado em 20 julho, 2020, de http://www.ancep.org.br/wp/wp-content/uploads/2013/12/INDICADORES-

COMISS\%C3\%830-REGIONAL-final.pdf.

Bain, J. S. (1956). Barriers to New Competition. Cambridge, Harvard U. P.

Bain, J. S. (1968). Industrial Organization. Nova York: John Wiley \& Sons Inc.

Baltagi, B. H. (1995). Econometric analysis of panel data. Cambridge University Press.

Bateman, H., \& Mitchell, O. (2004). New evidence on pension plan design and administrative expenses: the Australian experience. Journal of pension economics and finance, 3(1), 63-76.

https://doi.org/10.1017/S1474747204001465

Bauer, R., Cremers, K.J.M., \& Frehen, R.G.P. (2010). Pension fund performance and costs: small is beautiful, Tilburg University, MPRA Paper No. 23556.

Besanko, D., Dranove, D., Shanley, M., \& Schaefer, S. (2009). A Economia da Estratégia, $3^{a}$ ed. Bookman Editora.

Bikker, J. A. (2017). Is there an optimal pension fund size? A scale-economy analysis of administrative costs. Journal of risk and insurance, Malvern, USA, 8(2), 739-769. https://doi.org/10.1111/jori.12103

Bikker, J. A., \& De Dreu, J. (2009). Operating costs of pension funds. Journal of pension economics and finance, 8(1), 63-89. https://doi.org/10.1017/S1474747207002995

Bikker, J. A., Steenbeek, O., \& Torracchi, F. (2012). The impact of scale, complexity, and service quality on the administrative costs of pension funds: a cross-country comparison. Journal of risk and insurance, 79(2), 477-514. https://doi.org/10.1111/j.1539-6975.2011.01439.x

Caetano, M. A, Boueri, R, \& Sachsida, A. (2015). Economias de escala e escopo na previdência complementar fechada brasileira. Economia Aplicada, 19(3), 481-505. http://dx.doi.org/10.1590/14138050/ea13262

Canback, S., Samouel, P., \& Price, D. (2006). Do diseconomies of scale impact firm size and performance? Journal of Managerial Economics, 4(1), 27-70. Recuperado em 11 junho, 2019, de https://citeseerx.ist.psu.edu/viewdoc/download?doi=10.1.1.587.9815\&rep=rep1\&type=pdf

Caswell, J. (1976). Economic efficiency in the pension plan administration: a study of the construction industry. Journal of risk and insurance, 43(2), 257-273. Recuperado em 2 maio, 2015, de https://www.jstor.org/stable/251979?seq=1

Chatterton, M., Smyth, E., \& Darby, K. (2010). Pension scheme administrative costs, Department for Work and Pensions, Working Paper No 91, London.

Comissão Interministerial de Governança Corporativa e de Administração de Participações Societárias da União (CGPAR). Resolução no 25, de 06 de dezembro de 2018. Diário Oficial [da] República Federativa do Brasil, Poder Executivo, Brasília, DF, 07 dez. 2018. Seção 1, p. 201, 2018.

Conselho de Gestão da Previdência Complementar (CGPC). Resolução № 29, de 31 de agosto de 2009. Diário Oficial [da] República Federativa do Brasil, Poder Executivo, Brasília, DF, 10 set. 2009. Seção 1, p.51-52, 2009.

Conselho Monetário Nacional (CMN). Resolução oㅜ 4.661, de 25 de maio de 2018. Diário Oficial [da] República Federativa do Brasil, Poder Executivo, Brasília, DF, 29 mai. 2018. Seção 1, p.22-24, 2018.

Conselho Nacional de Previdência Complementar (CNPC). Resolução no 35, de 20 de dezembro de 2019. Diário Oficial [da] República Federativa do Brasil, Poder Executivo, Brasília, DF, 26 fev. 2020. Seção 1, p.7, 2020.

Cunha, C. M. P. (2018). Sponsor bias in pension fund administrative expenses: The Brazilian experience. Brazilian Administration Review, 15(1), e170072. http://dx.doi.org/10.1590/18077692bar2018170072

Griffin, D., \& Tversky, A. (1992). The weighing of evidence and the determinants of confidence. Cognitive Psychology, 24(3), 411-435. https://doi.org/10.1016/0010-0285(92)90013-R

Gujarati, D. N, \& Porter, D. C. (2011). Econometria Básica, 5aㅡ ed. Porto Alegre: AMGH Ed.

Hsin, P., \& Mitchell, O. (1997). Public pension plan efficiency, In: M. Gordon, O. Mitchell \& M. Twinney, (Org.), Positioning Pensions for the 21st Century, University of Pennsylvania Press, 187-205.

Kon, A. (1994). Economia industrial. São Paulo: Nobel. 
Koutsoyiannis, A. (1985). Modern Microeconomics, Macmillian, Second Edition.

Kupfer, D. (2002). Barreiras estruturais à entrada. in: kupfer, d., \& hasenclever, L. Economia Industrial: fundamentos teóricos e práticas no Brasil. Rio de Janeiro: Campus.

Lei Complementar no 109 de 29 de maio de 2001 (2001). Dispõe sobre o Regime de Previdência Complementar e dá outras providências. Diário Oficial [da] República Federativa do Brasil, Poder Executivo, Brasília, DF, 30 mai. 2001. Seção 1, p. 3, 2001.

Lei no 12.618 de 30 de abril de 2012 (2012). Institui o regime de previdência complementar para os servidores públicos federais titulares de cargo efetivo, inclusive os membros dos órgãos que menciona; fixa o limite máximo para a concessão de aposentadorias e pensões pelo regime de previdência de que trata 0 art. 40 da Constituição Federal; autoriza a criação de 3 (três) entidades fechadas de previdência complementar, denominadas Fundação de Previdência Complementar do Servidor Público Federal do Poder Executivo (Funpresp-Exe), Fundação de Previdência Complementar do Servidor Público Federal do Poder Legislativo (Funpresp-Leg) e Fundação de Previdência Complementar do Servidor Público Federal do Poder Judiciário (Funpresp-Jud); altera dispositivos da Lei no 10.887, de 18 de junho de 2004; e dá outras providências. Diário Oficial [da] União, Poder Executivo, Brasília, DF, 02 mai. 2012. Seção 1, p. 2, 2012.

Malhotra, D. K., Martin, R., \& Mcleod, R. W. (2009) Cost efficiencies and the selection of closed-end funds. Financial Services Review, 18(2), 105-122. Recuperado em 2 maio, 2015, de

https://go.gale.com/ps/anonymous?id=GALE\%7CA219649562\&sid=googleScholar\&v=2.1\&it=r\&linkaccess= abs\&issn $=10570810 \& p=A O N E \& s w=W$

Maluf, L. A. F. F. (2002). A evolução das teorias de organização industrial e seus determinantes na configuração da estrutura da indústria e conduta das firmas. $109 \mathrm{f}$. Dissertação (Mestrado em Economia) Programa de Pós-Graduação em Economia, Universidade Federal de Santa Catarina, Florianópolis, 2002.

MitchelL, O., \& Andrews, E. (1981). Scale economies in private multi-employer pension systems. Industrial and Labor Relations Review, 34(4), 522-530. https://doi.org/10.1177/001979398103400403

Pasqualeto, J. C. M. (2015). Os fatores impactantes dos custos administrativos nos fundos de pensão brasileiros. 79 f. Dissertação (Mestrado em Ciências Contábeis) - Escola de Gestão e Negócios da Universidade do Vale do Rio dos Sinos (Unisinos), São Leopoldo, 2015.

Pasqualeto, J. C. M., Costa, A. B., Etchebest, L. C., Silva, M. P., \& Padilha, R. T. L. (2014). Custos administrativos dos fundos de pensão brasileiros: uma análise entre os patrocínios públicos e privados. Revista de Administração e Contabilidade, 6(3), p. 38-50. Recuperado em 2 maio, 2015, de http://www.reacfat.com.br/index.php/reac/article/view/98

Pereira, C. A. P., Niyama, J. K., \& Sallaberry, J. D. (2013). A economia de escala no custo administrativo dos fundos de pensão brasileiros. Anais do Congresso Brasileiro de Custos, Uberlândia, Minas Gerais, Brasil, 2013.

Porter, M. (1985). Competitive Advantage: Creating and sustaining superior performance. New York: The Free Press.

Possas, M. L. (1987). Estruturas de mercado em oligopólio. 2ª ed. São Paulo: Hucitec.

Scherer, F.M., \& Ross, D. (1990). Industrial market structure and economic performance. $3^{\underline{a}}$ ed. Chicago: Raud Mc Nally \& Co.

Superintendência de Seguros Privados (SUSEP) (2017). Previdência complementar aberta. Recuperado em 24 janeiro, 2017, de http://www.susep.gov.br/menu/informacoes-ao-publico/planos-e-produtos/previdenciacomplementar-aberta\#duvidasfaq

Superintendência Nacional de Previdência Complementar (PREVIC) (2020a). Balancetes Contábeis Consolidados. Brasília, DF: PREVIC, 2020a. Recuperado em 20 junho, 2020, de http://www.previc.gov.br/acesso-a-informacao/dados-abertos/balancetes-contabeis/consolidado

Superintendência Nacional de Previdência Complementar (PREVIC) (2020b). Balancetes Contábeis de Planos. Brasília, DF: PREVIC, 2020b. Recuperado em 20 junho, 2020, de http://www.previc.gov.br/acessoa-informacao/dados-abertos/balancetes-contabeis/balancetes-de-planos

Superintendência Nacional de Previdência Complementar (PREVIC) (2020c). Divulgação das Despesas Administrativas das Entidades Fechadas de Previdência Complementar. Brasília, DF: PREVIC, 2020c. (Série de Estudos, ํo 7 e oㅡ 8). Recuperado em 20 junho, 2020, de http://www.previc.gov.br//central-deconteudos/publicacoes/series-de-estudo/serie-de-estudos-1 
Teixeira, R. F. A. P., Santos, O. M., \& Macedo, M. A. S. (2020). Gerenciamento de resultados em entidades fechadas de previdência complementar. Anais do XX USP International Conference in Accounting, 2020,

São Paulo, São Paulo, Brasil: Online.

\title{
NOTAS
}

\section{AGRADECIMENTOS}

Não se aplica.

\section{CONTRIBUIÇÃO DE AUTORIA}

Concepção e elaboração do manuscrito: R. F. A. P. Teixeira, A. Rodrigues

Coleta de dados: R. F. A. P. Teixeira

Análise de dados: R. F. A. P. Teixeira

Discussão dos resultados: R. F. A. P. Teixeira

Revisão e aprovação: R. F. A. P. Teixeira, A. Rodrigues

\section{CONJUNTO DE DADOS DE PESQUISA}

Todo o conjunto de dados que dá suporte aos resultados deste estudo foi publicado no próprio artigo.

\section{FINANCIAMENTO}

\author{
Não se aplica.
}

\section{CONSENTIMENTO DE USO DE IMAGEM}

Não se aplica.

\section{APROVAÇÃO DE COMITÊ DE ÉTICA EM PESQUISA \\ Não se aplica.}

\section{CONFLITO DE INTERESSES}

Não se aplica.

\section{LICENÇA DE USO}

Os Direitos Autorais para artigos publicados neste periódico são do autor, com direitos de primeira publicação para a Revista. Em virtude de aparecerem nesta Revista de acesso público, os artigos são de uso gratuito, com atribuições próprias, em aplicações educacionais, de exercício profissional e para gestão pública. A Revista adotou a licença Creative Commons Atribuição 4.0 Internacional - CC BY NC ND. Esta licença permite acessar, baixar (download), copiar, imprimir, compartilhar, reutilizar e distribuir os artigos desde que com a citação da fonte, atribuindo os devidos créditos de autoria. Nesses casos, nenhuma permissão é necessária por parte dos autores ou dos editores. Autores têm autorização para assumir contratos adicionais separadamente, para distribuição não-exclusiva da versão do trabalho publicada nesta revista (ex.: publicar em repositório institucional ou um capítulo de livro).

\section{PUBLISHER}

Universidade Federal de Santa Catarina. Curso de Ciências Contábeis e Programa de Pós-graduação em Contabilidade. Publicação no Portal de Periódicos UFSC. As ideias expressadas neste artigo são de responsabilidade de seus autores, não representando, necessariamente, a opinião dos editores ou da universidade.

\section{EDITORES}

Carlos Eduardo Facin Lavarda e Suliani Rover

\section{HISTÓRICO}

Recebido em: 16/12/2019 - Revisado por pares em: 08/06/2020 - Reformulado em: 05/09/2020 Recomendado para publicação em: 15/10/2020 - Publicado em: 15/01/2021

\footnotetext{
i Em 2017 existiam 304 EFPC e em 2018 esse número se reduziu para 296 (PREVIC, 2020c). Todavia, somente 225 EFPC no ano de 2017 forneceram os dados necessários ao cálculo de todas estatísticas, bem como, o mesmo fato ocorreu para apenas 230 EFPC em 2018.
} 